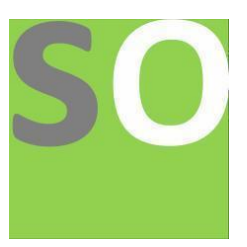

Article title: Optimization Of A Centrifugal Spinning Machine

Authors: MEIARUL RAJENDRAN[1]

Affiliations: MECHANICAL, ANAND INSTITUTE OF HIGHER TECHNOLOGY, Kalasalingam Nagar IT Corridor, Old Mahabal Road, Kazhipattur, Tamil Nadu 603103.[1]

Orcid ids: 0000-0003-4387-7091[1]

Contact e-mail: meiarulr@gmail.com

License information: This work has been published open access under Creative Commons Attribution License http://creativecommons.org/licenses/by/4.0/, which permits unrestricted use, distribution, and reproduction in any medium, provided the original work is properly cited. Conditions, terms of use and publishing policy can be found at https://www.scienceopen.com/.

Preprint statement: This article is a preprint and has not been peer-reviewed, under consideration and submitted to ScienceOpen Preprints for open peer review.

DOI: 10.14293/S2199-1006.1.SOR-.PPULVZA.v1

Preprint first posted online: 14 September 2021

Keywords: centrifugal spinning machine, mat, micro and nano-fibers, safer, efficient method 


\title{
OPTIMIZATION OF CENTRIFUGAL SPINNING MACHINE
}

\author{
Meiarul $\mathrm{R}^{1^{*}}$ \\ ${ }^{1}$ Mechanical Engineering Department, Anand Institute of Higher Technology, Kalasalingam Nagar IT Corridor, Old \\ Mahabalipuram Road, Kazhipattur, Tamil Nadu 603 103, India \\ E-mail: meiarulr@gmail.com
}

\begin{abstract}
We were all living in the world of technology, where the science had been developing for each and every seconds such as new technologies, new inventions and new ideas. In which, we would like to introduce a new idea by using centrifugal spinning method. Where, it is has been recently used for the production of micro and nano-fibers and it is also a safer and more efficient method for producing micro and nano-fibers when compared to all the fibers production method. Our concept is to reduce the manufacturing cost of the centrifugal spinning machine. Because the manufacturing cost of the single machine in India is about Rs.2.5 to 3 lakhs, by the way we would like to produce a machine at a low cost and by using the machine we produce the mat which has the same efficiency as compared to the mat produced by the original machine.
\end{abstract}

Key words: centrifugal spinning machine, mat, micro and nano-fibers, safer, efficient method.

\section{INTRODUCTION}

In the recent years, the use of nano-fibers has been widely used in all industries. In which, the nanofibers are those fibers within the diameter range of 1 to 100 nanometers. And it can be generated from different polymers which has different mechanical properties and applications based on what type of polymer we used to produce the nanofiber (or) mat. And it is widely used in real life applications like tissue engineering, drug delivery, cancer diagnosis, lithium-air battery, air filtration, oil-water separation, and sportswear textiles etc. In which, many methods had been used by the industries to produce the nanofibers such as electrospinning, multi jet electrospinning, bi-component spinning, drawing, phase separation, force spinning (or) centrifugal spinning. Where, we choose centrifugal spinning method because it is the most efficient, more economical, low cost and safer method for producing nano-fiber. Where, we had modified the centrifugal spinning machine by introducing the top-down approach in which the molten polymer solution falls directly into the spinneret from the top of the barrel connected with the band heater, and it comes out through the orifice which is located in the bottom of the spinneret and collected in the collecting drum which is placed just 
opposite to the spinneret. The following components are used in this machines are PID temperature controller, SSR, RTD sensor, 1 kilowatt mica band heater, 145 watts ac motor, rack and pinion gears, pillow block bearings etc. The PID temperature controller stands for proportional integral derivative controller. It uses closed control loop feedback mechanism. Where, it calculates an error value as the difference between a desired set point (SP) and a measured process variable (PV) and applies a correction based on proportional, integral and derivative terms. It is widely used in industrial control systems and a variety of other applications that require continuous modulation control. The SSR stands for solid state relay which is used for ON and OFF the band heater which is connected to the PID controller. The RTD temperature sensor stands for resistance temperature detector these are sensors used to measure Temperature. They are normally constructed of platinum, copper, nickel and nickel iron alloy. It acts as an electrical transducer that converts and changes the temperature into voltage signals by the measurement of resistance. Here, we are going to use PT - 100 temperature sensor, it is a contact type RTD sensor. And we are going to use 1000 watts mica band heater it is an indirect form of industrial heating and it is used to heat the outer surface of drums (or) tubes for the gradual transfer of heat. We had chosen mica band heater, due to low cost and high efficiency. The rack is a type of linear actuator that includes a circular gear (the pinion) that engages a linear gear (the rack). It is used to translate rotational motion into linear motion and it is used for pushing the molten polymer solution manually to give some forces on the solution to hit the surface of the spinneret and comes out through the orifice. A collecting drum made up of stainless steel which has excellent corrosion resistance, very tough and scale resistance at high temperature which is used to collect the nano-fibers in the form of mat coming out from the orifice where it also acts as a protective barrier to prevent accidental damages.

\section{A. SPECIFICATIONS OF MOTOR}

\begin{tabular}{cc}
\hline PARAMETER & VALUES \\
\hline WATTS & 145 \\
\hline VOLTS & 220 \\
\hline R.P.M & 6500 \\
\hline AMPS & 0.75 \\
\hline
\end{tabular}


Table 1.1 Motor Specifications

\section{METHODOLOGY}

In this the mat is produced by using "centrifugal force" so, the following steps are used for preparing the mat by using the centrifugal spinning machine:

a. First the polycaprolactone solution is prepared by dissolving (12wt. /v \%) of PCL in TFE (2, 2, 2Trifluroethanol) and stirring it in a magnetic stirrer to get uniform fibers for the centrifugal spinning process.

b. The centrifugal spinning machine consist of two segments the top segment consist of barrel connected with a band heater, PID temperature controller, rack and pinion, nozzle, SSR, RTD sensor and the bottom segment consist of spinneret, collecting drum, motor etc.

c. The melted polymer solution is poured into the barrel where, the barrel is maintained at a temperature of 60 degree Celsius by using the band heater connected to the PID controller through SSR.

d. The RTD sensor is connected to the band heater to give feedback for the PID controller. In which we have to maintain the temperature of the barrel at a constant rate because, to produce high quality of nanofibers the surface tension and viscosity of the fluid must be decreased by increasing the working temperature which led to the formation of nanofibers.

e. The evaporation rate, viscosity of the solution and surface tension affects the quality of nanofiber which can be minimized by maintaining a suitable working temperature.

f. The speed of the spinneret is maintained at a speed of 3000 to 4000RPM (rotational per minute) for the formation of nanofiber. Because, when the speed of the spinneret is low the centrifugal force cannot overcome the surface tension which may cause the solution to stuck in the spinneret itself.

g. The distance of the collecting drum is fixed about $15 \mathrm{~cm}$ (or) $150 \mathrm{~mm}$ from the spinneret. When the distance of the collecting drum is too short the fiber coming out from the spinneret will not stretch and the diameter of the fiber produced will be very large.

h. The diameter of the orifice in the spinneret can be made between 0.1 to $1 \mathrm{~mm}$. where we had chosen $0.5 \mathrm{~mm}$ because it reduces beads and form fine dimeter. 
i. Finally, the nanofiber in the form of mat is collected in the collecting drum and separated from it by manually by hands without using any chemicals to separate the mat from the collecting drum.

\section{EXPERIMENTAL}

\subsection{FORMULA USED}

1. Centrifugal force, $F_{c}=\operatorname{mr} \omega^{2}($ or $) \frac{m v^{2}}{r}(\mathrm{~N})$

$\omega=\frac{2 \pi N}{60}($ Radian $)$

$F_{c}=$ centrifugal force, $\mathrm{N}$

$\mathrm{m}=$ mass of the material, $\mathrm{kg}$

$\mathrm{r}=$ radius of the spinneret, $\mathrm{m}$

$\omega=$ speed of spinneret, Radian

$\mathrm{v}=$ linear speed, $\mathrm{m} / \mathrm{s}$

$\mathrm{N}=$ speed (or) angular speed, RPM (Revolution Per Minute)

2. Pressure, $\mathrm{P}=0.5 \times \rho \times \gamma^{2} \times\left(1-D_{i} / D_{e}\right)\left(\mathrm{kg} / \mathrm{ms}^{2}\right)$

$\rho=$ Density of the resin solution, $\mathrm{kg} / \mathrm{m}^{3}$

$\gamma=$ circumferential speed, $\mathrm{m} / \mathrm{s}$

$D_{i}=$ The internal diameter, $\mathrm{m}$

$D_{e}=$ External diameter of the whirler plate, $\mathrm{m}$

3. Mass, $\mathbf{M}=\mathrm{A}^{*} \mathrm{~L} * \mathrm{P}$ (or) $\rho^{*} \mathrm{v}(\mathrm{kg})$

$\mathrm{M}$ (or) $\mathrm{m}=$ mass, $\mathrm{kg}$

Mass $=$ density $*$ volume

$\mathrm{L}=$ length, $\mathrm{m}$

$\mathrm{A}=$ cross sectional area $=\mathrm{BH}-\mathrm{bh}, \mathrm{m}^{2}$

$\rho=$ density, $\mathrm{kg} / \mathrm{m}^{3}$

$\mathrm{v}=$ volume, $\mathrm{m}^{3}$

4. Volume of hollow rectangle $=\mathrm{E} . \mathrm{V}-\mathrm{I} . \mathrm{V}\left(\mathrm{m}^{3}\right)$

E. $\mathrm{V}=$ External volume $=\mathrm{L} * \mathrm{~B} * \mathrm{H}, \mathrm{m}^{3}$

$\mathrm{I} . \mathrm{V}=$ Internal volume $=\mathrm{L} * \mathrm{~B} * \mathrm{H}, \mathrm{m}^{3}$ 
$\mathrm{L}=$ length, $\mathrm{m}$

$\mathrm{B}=$ breadth (or) width, $\mathrm{m}$

$\mathrm{H}=$ height, $\mathrm{m}$

5. Volume of solid rectangle $=\mathrm{L} * \mathrm{~B} * \mathrm{H}\left(\mathrm{m}^{3}\right)$

6. Volume of cylinder $=\pi r^{2} \mathrm{~h}\left(\mathrm{~m}^{3}\right)$

$\mathrm{r}=$ radius, $\mathrm{m}$

$\mathrm{h}=$ height, $\mathrm{m}$

7. Center of gravity,

$\mathrm{X}=\mathrm{L} / 2(\mathrm{~m})$

$\mathrm{Y}=\frac{V_{1} Y_{1}+V_{2} Y_{2}+V_{3} Y_{3}}{V_{1}+V_{2}+V_{3}}(\mathrm{~m})$

$\mathrm{L}=$ Length, $\mathrm{m}$

$\mathrm{Y}=\mathrm{h} / 2, \mathrm{~m}$

$\mathrm{h}=$ height, $\mathrm{m}$

\subsection{DESIGN CALCULATION}

\section{center of gravity}

Length of the rectangle $=45.8 \mathrm{~cm}$, breadth of the rectangle $=40.6 \mathrm{~cm}$, depth $=1.7 \mathrm{~cm}$

Height of the rectangle $=30 \mathrm{~cm}$.

For finding the center of gravity, first we have to find the volume of all the three sections.

Here we take three sections namely,

1. Hollow rectangle (hollow cuboid)

2. Solid rectangle

3. Solid cylinder

Here, all the three sections are symmetrical about $\mathbf{y}-\mathbf{a x i s}$ and all the three sections are having same vertical axis.

SYMMENTRY ABOUT Y - AXIS 


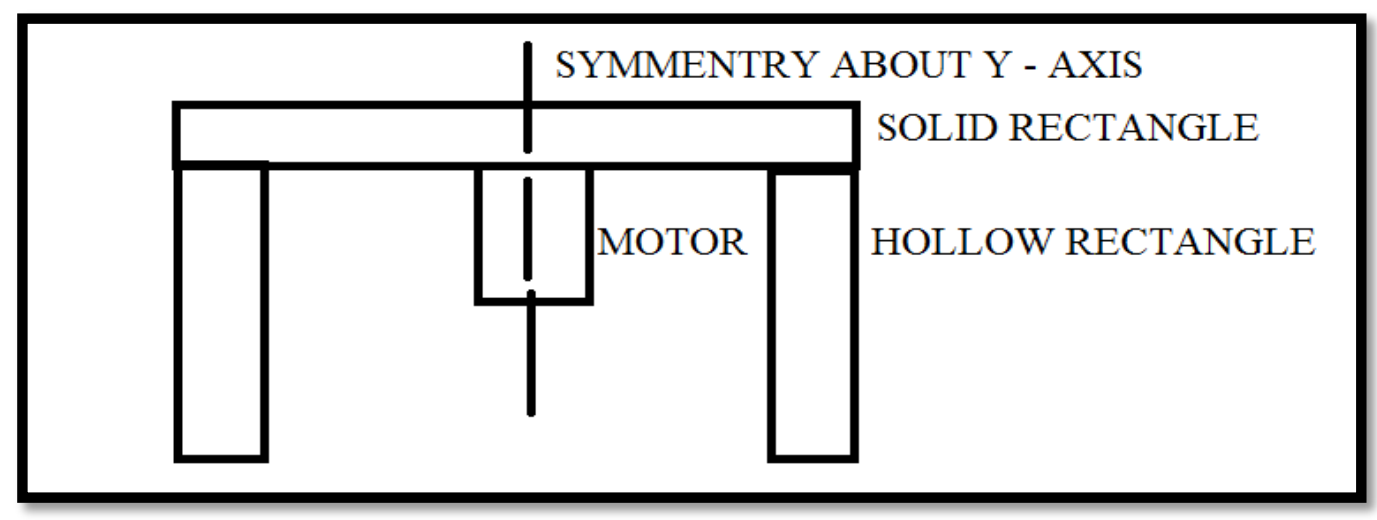

Figure. 1: symmetry about $\mathbf{y}$ - axis

\section{HOLLOW RECTANGLE (HOLLOW CUBOID)}

$>$ We are going to use square type mild steel hollow section.

$>$ Whose dimensions are length $=2.5 \mathrm{~cm}$, breadth $=2.5 \mathrm{~cm}$, thickness $=0.2 \mathrm{~cm}$.

$>$ And the external dimensions of the rectangle are length $=45.8 \mathrm{~cm}$, breadth $=40.6 \mathrm{~cm}$, height $=30 \mathrm{~cm}$.

$>$ Internal dimensions are length $=40.8 \mathrm{~cm}$, breadth $=35.6 \mathrm{~cm}$, height $=30 \mathrm{~cm}$.

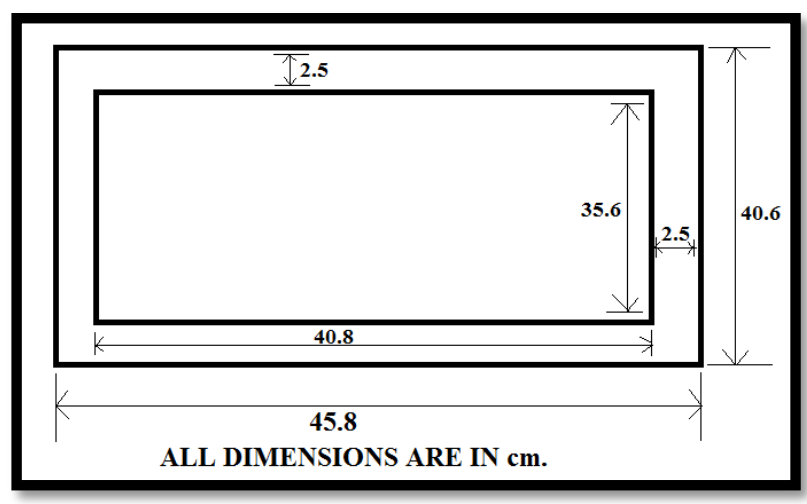

Figure. 2: hollow cuboid

External volume $(\mathrm{E} . \mathrm{V})=\mathrm{L} * \mathrm{~B} * \mathrm{H}$

$=>45.8 * 40.6 * 30$

E.V $=55784.4 \mathrm{~cm}^{3}$

Internal volume $(\mathrm{I} . \mathrm{V})=\mathrm{L} * \mathrm{~B} * \mathrm{H}$

$\Rightarrow 40.8 * 35.6 * 30$

$\mathrm{I} . \mathrm{V}=43574.4 \mathrm{~cm}^{3}$

Volume of hollow rectangle $=\mathrm{E} . \mathrm{V}-\mathrm{I} . \mathrm{V}$ 
Volume of hollow rectangle $\left(V_{1}\right)=12210 \mathrm{~cm}^{3}$

$Y_{1}=\mathrm{h} / 2=45.8 / 2=22.9 \mathrm{~cm}$.

\section{SOLID RECTANGLE}

$>$ We are going to use solid wood rectangle.

$>$ Whose dimensions are length $=45.8 \mathrm{~cm}$, breadth $=40.6 \mathrm{~cm}$, height $=1.7 \mathrm{~cm}$.

Volume of rectangle $=1 * \mathrm{w} * \mathrm{~h}$

$$
=>45.8 * 40.6 * 1.7
$$

Volume of rectangle $\left(V_{2}\right)=3161.11 \mathrm{~cm}^{3}$

$Y_{2}=\mathrm{h} / 2=1.7 / 2=0.85 \mathrm{~cm}$

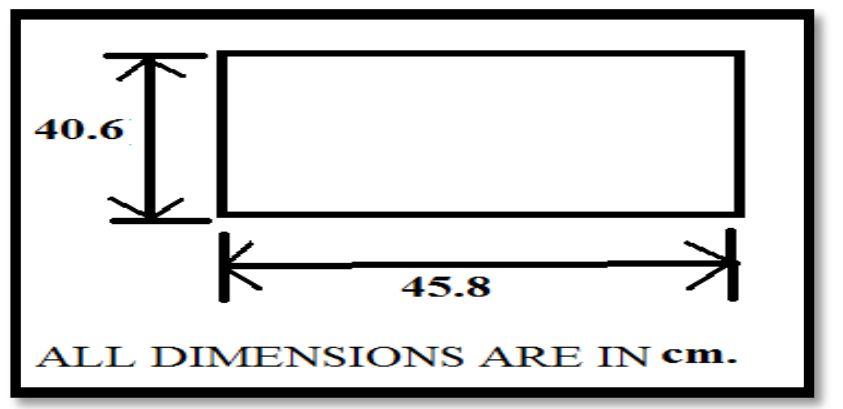

Figure. 3: solid rectangle

\section{SOLID CYLINDER}

Here we are going to consider the cylinder as fully solid and it is made up of aluminum.

$>$ Whose dimensions are diameter of the motor $(\mathrm{D})=32 \mathrm{~cm}$, radius $(\mathrm{r})=32 / 2=16 \mathrm{~cm}$, height $(\mathrm{h})=18 \mathrm{~cm}$.

Volume of cylinder $=\pi r^{2} \mathrm{~h}$

$$
=>\pi\left(16^{2}\right) * 18
$$

Volume of cylinder $\left(V_{3}\right)=14476.45 \mathrm{~cm}^{3}$

$Y_{3}=\mathrm{h} / 2=18 / 2=9 \mathrm{~cm}$. 


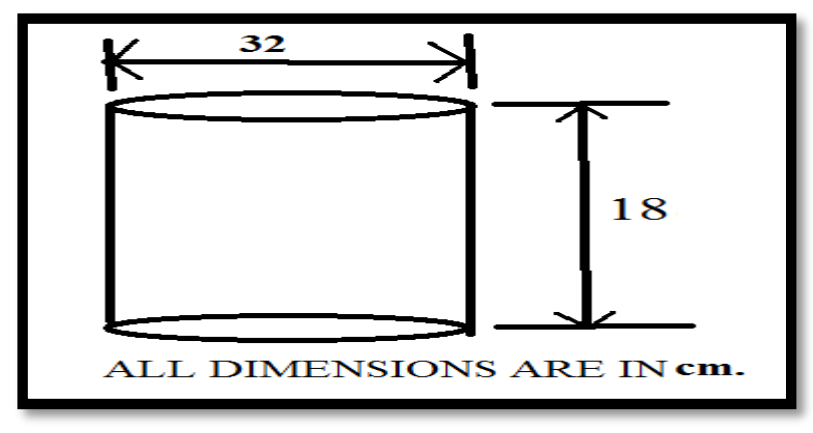

Figure. 4: solid cylinder

\section{CENTER OF GRAVITY}

Since, it is symmetry about $\mathbf{y}-\mathbf{a x i s}$.

$$
\begin{aligned}
X & =45.8 / 2 \Rightarrow 22.9 \mathrm{~cm} \\
Y & =\frac{V_{1} Y_{1}+V_{2} Y_{2}+V_{3} Y_{3}}{V_{1}+V_{2}+V_{3}} \\
& \Rightarrow \frac{12210(22.9)+3161.11(0.85)+14476.45(9)}{12210+3161.11+14476.45} \\
& \Rightarrow>\frac{412583.9935}{29847.56} \\
Y & \Rightarrow>13.823 \mathrm{~cm} .
\end{aligned}
$$

$>$ Therefore, center of gravity is,

1. $\mathrm{X}=22.9 \mathrm{~cm}$ (or) $0.229 \mathrm{~m}$.

2. $Y=13.823 \mathrm{~cm}$ (or) $0.138 \mathrm{~m}$.

\section{TO FIND CENTRIFUGAL FORCE}

\section{Calculating centrifugal force $\left(F_{c}\right)$,}

\section{Formula}

Centrifugal force, $F_{c}=\operatorname{mr} \omega^{2}$ (or) $\frac{m v^{2}}{r}$

$\omega=\frac{2 \pi N}{60}$

$F_{c}=$ centrifugal force, $\mathrm{N}$

$\mathrm{M}=$ mass of the material, $\mathrm{kg}$

$\mathrm{R}=$ radius of the spinneret, $\mathrm{m}$

$\omega=$ speed of spinneret, Radian

$\mathrm{v}=$ linear speed, $\mathrm{m} / \mathrm{s}$ 
$\mathrm{N}=$ speed (or) angular speed, RPM (Revolution Per Minute)

Where,

Speed $(\mathrm{N})=3000 \mathrm{RPM}$

Radius $(\mathrm{r})=5 \mathrm{~cm}=0.05 \mathrm{~m}$

$\omega=\frac{2 \pi(3000)}{60}=>\frac{18849.556}{60}$

$\omega=314.159$ radian.

Where, CIRCUMFERENCE $=$ DISTANCE AROUND CIRCLE

We are going to take,

$>1$ REVOLUTION $=2 \pi r$

We need to convert revolution per minute to meter per second.

To find velocity, $\mathrm{v}$

$>3000 \frac{\mathrm{rev}}{\min } \times \frac{1 \mathrm{~min}}{60 \mathrm{sec}} \times \frac{2 \pi(0.05)}{1 \mathrm{rev}}$

$$
\mathrm{v}=>3000 \times \frac{1}{60} \times 0.3141=15.705
$$

$>$ For $1 \mathrm{sec}$ the spinneret travels $=1570.5 \mathrm{~cm} / \mathrm{s}$ (or) $15.705 \mathrm{~m} / \mathrm{s}$

Next, we are going to find mass of all the three materials,

\section{Mass of all the three materials,}

\section{[1] HOLLOW RECTANGLE}

$$
\mathrm{M}=\mathrm{A} * \mathrm{~L} * \mathrm{P} \text { (or) } \rho^{*} \mathrm{v}
$$

Where,

$$
\begin{aligned}
& \text { M (or) } m=\text { mass } \\
& \text { Mass = density*volume } \\
& \mathrm{L}=\text { length } \\
& \mathrm{A}=\text { cross sectional area }=\mathrm{BH}-\mathrm{bh} \\
& \rho=\text { density } \\
& \mathrm{v}=\text { volume } \\
& \mathrm{A}=(40.6 * 45.8)-(40.8 * 35.6)=>407 \\
& \mathrm{~A}=407 \mathrm{~cm}^{2} \text { (or) } 0.0407 \mathrm{~m}^{2} .
\end{aligned}
$$


Where the density of mild steel $(\rho)=7850 \mathrm{~kg} / \mathrm{m}^{3}$

Length $(\mathrm{L})=30 \mathrm{~cm}=0.3 \mathrm{~m}$

$\mathrm{m}=0.0407 * 0.3 * 7850$

$M_{1}=95.84 \mathrm{~kg}$.

\section{[2] SOLID RECTANGLE}

$$
\mathrm{M}=\rho^{*} \mathrm{~V}
$$

Volume $=>3161.11 \mathrm{~cm}^{3}$ (or) $3.161 * 10^{-3}$

Where, density of wood $(\rho)=>805-960 \mathrm{~kg} / \mathrm{m}^{3}$

We take $\rho=883 \mathrm{~kg} / \mathrm{m}^{3}$

$\mathrm{m}=883 *\left(3.161 * 10^{-3}\right)$

$=>883 * 0.003161$

$M_{2}=2.791 \mathrm{~kg}$.

\section{[3] CYLINDER}

$\mathrm{M}=\rho^{*} \mathrm{~V}$

Volume $(\mathrm{v})=14476.45 \mathrm{~cm}^{3}$ (or) $0.01447 \mathrm{~m}^{3}$

Where, density of aluminum $(\rho)=>2640-2810 \mathrm{~kg} / \mathrm{m}^{3}$

We take $\rho=2710 \mathrm{~kg} / \mathrm{m}^{3}$

$\mathrm{m}=2710 * 0.01447$

$M_{3}=39.23 \mathrm{~kg}$

TOTAL MASS $(\mathrm{M})=>M_{1}+M_{2}+M_{3}$

$\mathrm{M}=95.84+2.791+39.23$

Mass $(M)=137.861 \mathrm{~kg}$.

Next, we are going to calculate the centrifugal force and pressure by using the formula,

\section{A. CENTRIFUGal FORCE,}

$$
\begin{aligned}
& \mathrm{F}=\operatorname{mr} \omega^{2}(\mathrm{~N}) \\
& \Rightarrow(137.861) *(0.05) *(314.159)^{2}
\end{aligned}
$$




$$
\begin{aligned}
& \mathrm{F}=680315.62 \mathrm{~N} \\
& \mathrm{~F}=6.8032 * 10^{5} \mathrm{~N} \approx 6.803 * 10^{5} \mathrm{~N}
\end{aligned}
$$

$(\mathrm{OR})$

$$
\begin{aligned}
\mathrm{F} & =\frac{m v^{2}}{r} \\
& =>\frac{137.861 *(15.705)^{2}}{0.05}
\end{aligned}
$$

$\mathrm{F}=680060.11 \mathrm{~N}$

$\mathrm{F}=6.8006 * 10^{5} \approx 6.801 * 10^{5} \mathrm{~N}$

Thus, centrifugal force $\left(F_{c}\right)=6.803 * 10^{5} \mathrm{~N}$.

\section{B. PRESSURE}

$$
\begin{aligned}
& \mathrm{P}=0.5 \times \rho \times \gamma^{2} \times\left(1-D_{i} / D_{e}\right)\left(\mathrm{kg} / \mathrm{ms}^{2}\right) \\
& \rho=1145 \mathrm{~kg} / \mathrm{m}^{3} \\
& \gamma=\mathrm{r}^{*} \omega \mathrm{m} / \mathrm{s} \\
& \mathrm{r}=\mathrm{D}_{\mathrm{e}} / 2=0.277 / 2=0.1385 \mathrm{~m} \\
& \omega=314.159 \\
& \gamma=(0.1385)^{*}(314.159)=43.51 \mathrm{~m} / \mathrm{s} \\
& \gamma=43.51 \mathrm{~m} / \mathrm{s} \\
& D_{i}=0.273 \mathrm{~m} \\
& D_{e}=0.277 \mathrm{~m} \\
& \Rightarrow \quad 0.5 *(1145) *\left(43.51^{2}\right)^{*}(1-(0.273 / 0.277)) \\
& \Rightarrow \quad 15650.70 \mathrm{~kg} / \mathrm{ms}^{2}
\end{aligned}
$$

Thus, pressure $(\mathrm{P})=15650.70 \mathrm{~kg} / \mathrm{ms}^{2}=0.157 \mathrm{bar}$

Thus, the value of centrifugal force $\left(F_{c}\right)$ and pressure $(P)$ is calculated. 


\subsection{SCHEMATIC DIAGRAM}

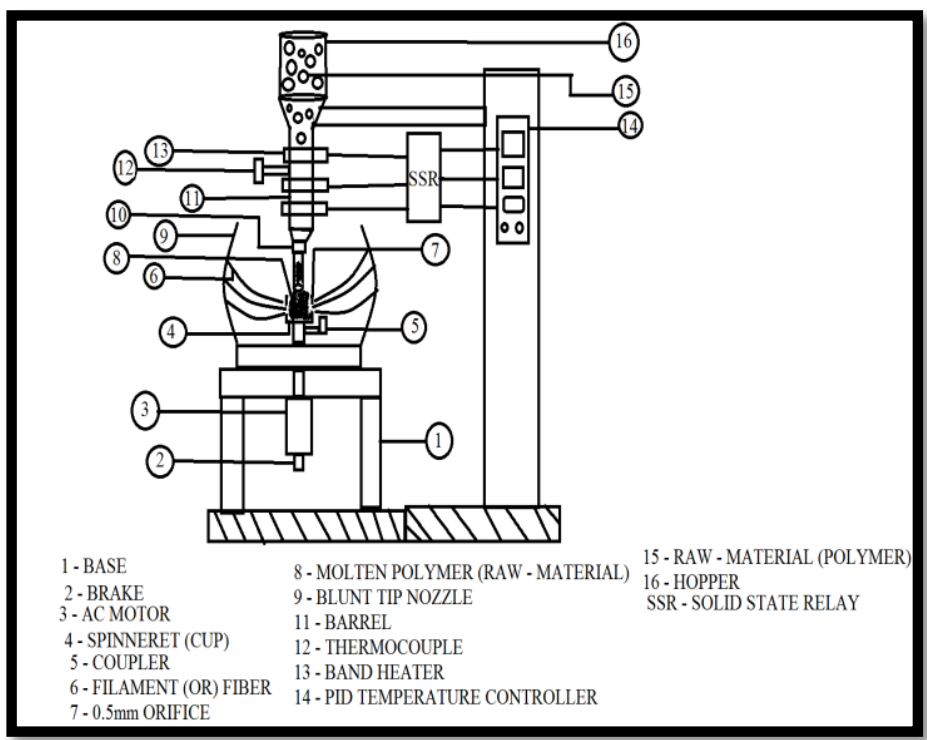

Figure. 5: centrifugal spinning machine

\subsection{SOLIDWORKS DESIGN MODEL}

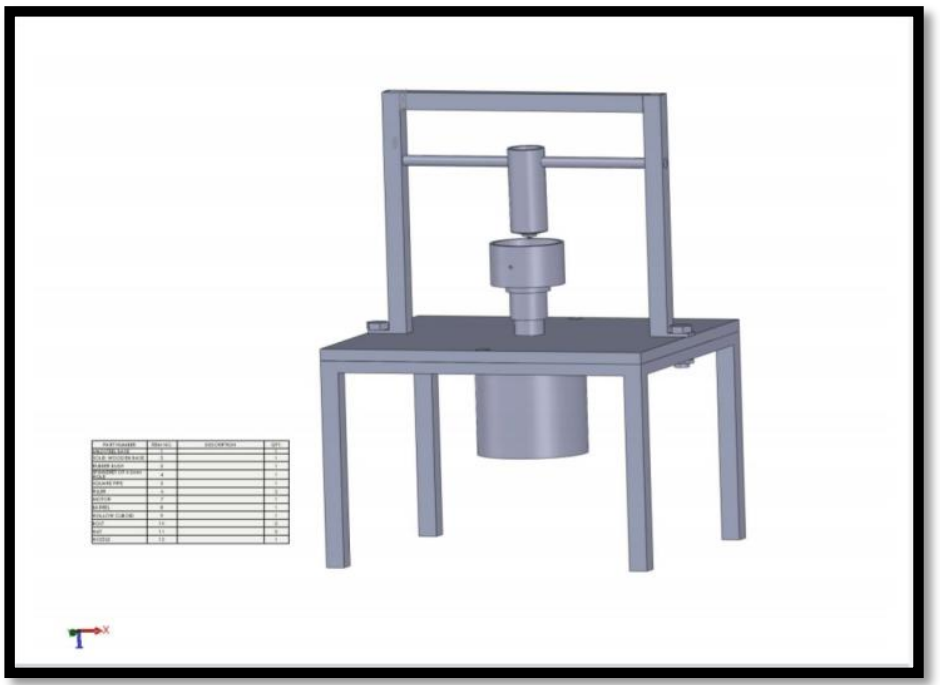

Figure. 6: solidworks design model 


\subsection{FABRICATION SETUP}
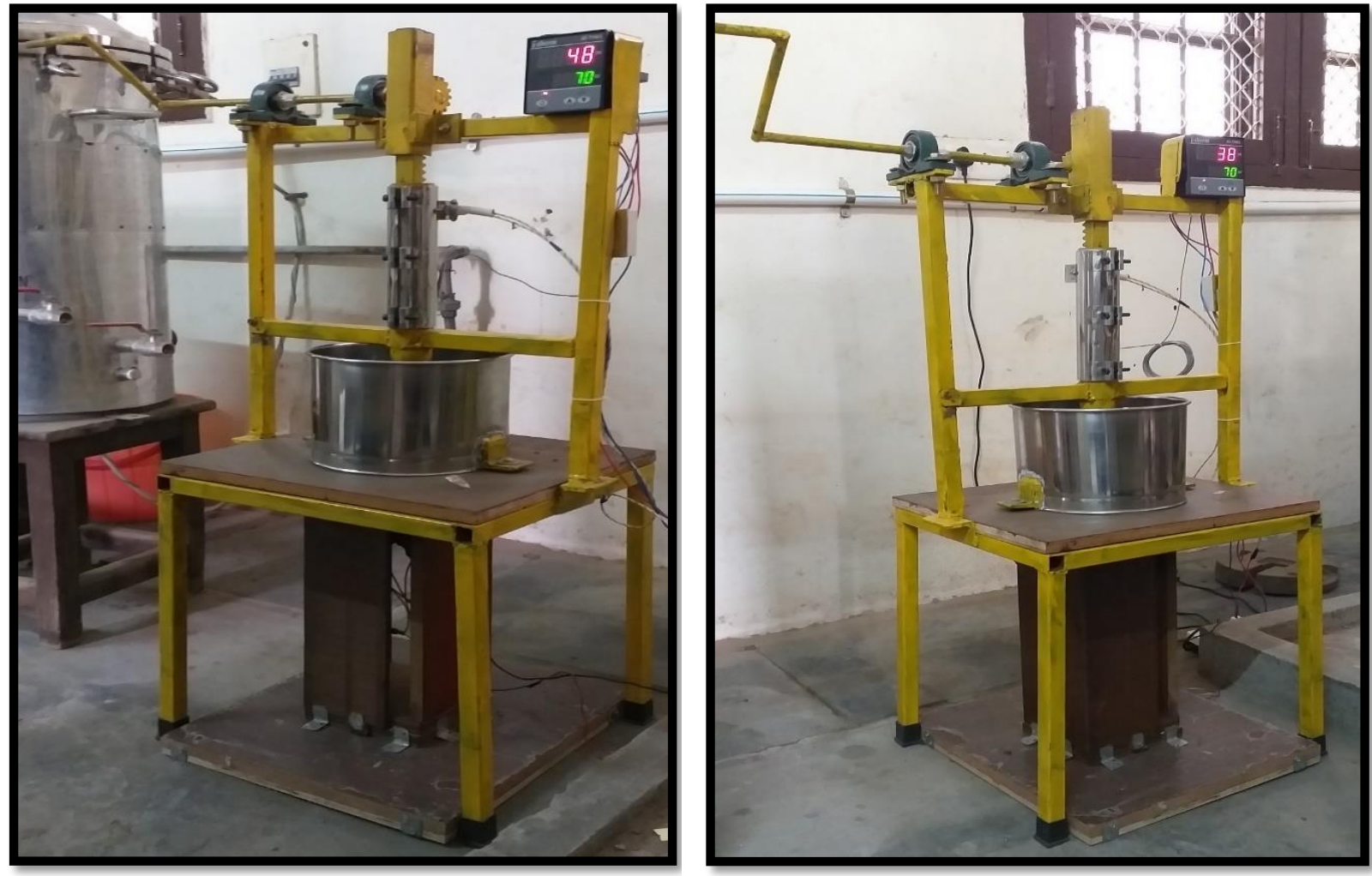

Figure. 7: left side and right side view of fabrication setup of centrifugal spinning machine

\subsection{SPINNERET ALONG WITH MOTOR}

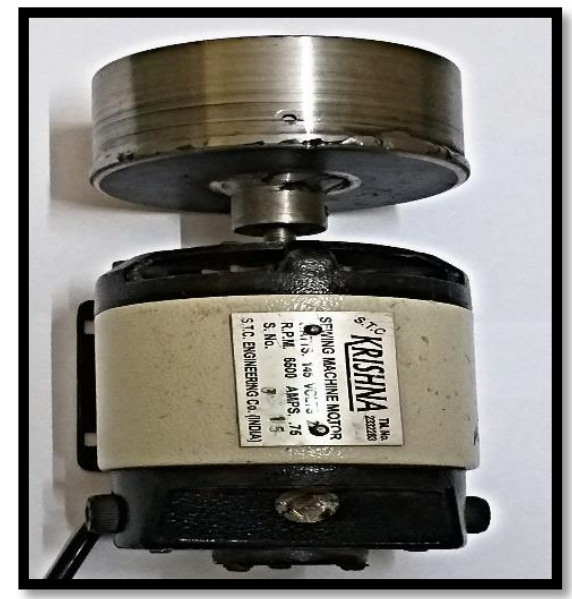

Figure. 8: spinneret along with motor 


\subsection{WIRING CONNECTION}

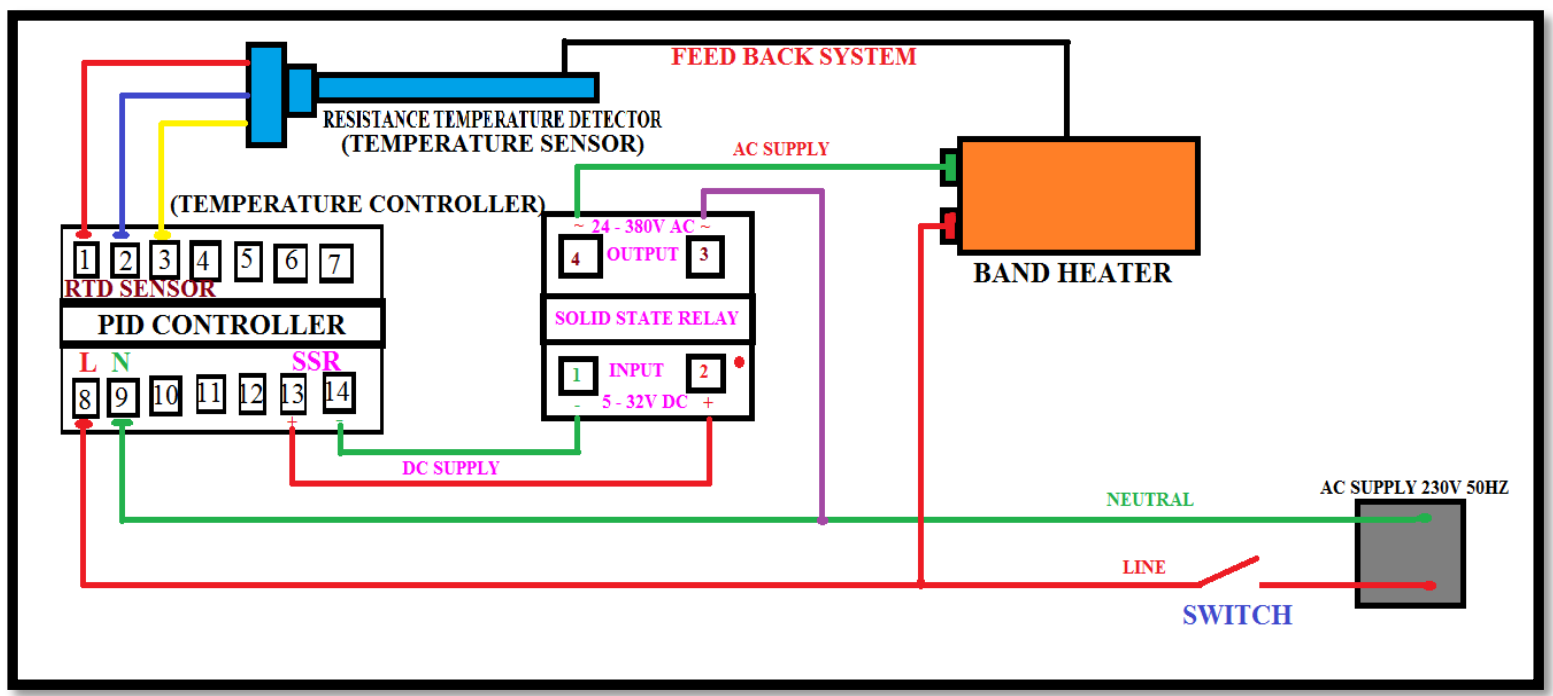

Figure. 9: wiring connection of centrifugal spinning machine

In this setup, the input AC power supply is given to the PID temperature controller in bottom of the $8^{\text {th }}$ and $9^{\text {th }}$ segment and the RTD sensor (temperature sensor) is connected in top of the $1^{\text {st }}, 2^{\text {nd }}$, and $3^{\text {rd }}$ segment of the PID controller. Where, the output of the PID temperature controller is DC. where, it produces 15 volts DC supply and it cannot be directly given to the band heater. Because the band heater works on AC supply only. So, we have to change the supply from DC to AC by using solid state relay (SSR) module. In SSR the input is DC supply and the output is AC supply. Where the output of the PID controller of $13^{\text {th }}$ positive supply is connected to the $2^{\text {nd }}$ positive supply of the SSR module and $14^{\text {th }}$ negative supply is connected to the $1^{\text {st }}$ negative supply of the SSR module. In the output of the SSR module any one segment either $3^{\text {rd }}$ (or) $4^{\text {th }}$ can be given to the $\mathrm{AC}$ power source and the other segment is given to the band heater. And in the band heater also any one line is given to the AC power source. And the other important function of the SSR is to ON and OFF the band heater when the signal comes from PID controller. The RTD (temperature) sensor is connected to the band heater to monitor the temperature of the band heater and gives feed back to the PID temperature controller. The main function of the PID controller is to check the temperature of the band heater by the use of RTD sensor.

Example: when we set a value (SV) of 60 degree Celsius in PID temperature controller, the controller measures the temperature of the band heater by the use of RTD and indicates the measuring value as the 
process variable $(\mathrm{PV})$ in the monitor. When the measured temperature goes above 60 degree Celsius the PID controller sends signal to the SSR module to cut off the current supply to the band heater and when the temperature goes below the 60 degree Celsius the PID controller sends signal to the SSR module to turn on power supply to the band heater to maintain at the same temperature. The PID temperature controller uses a closed control loop feedback mechanism.

\section{RESULTS AND DISCUSSION}

In this, the polycaprolactone mat is produced by using centrifugal spinning machine and the photographic image and scanning electron microscope (SEM) image are produced here,

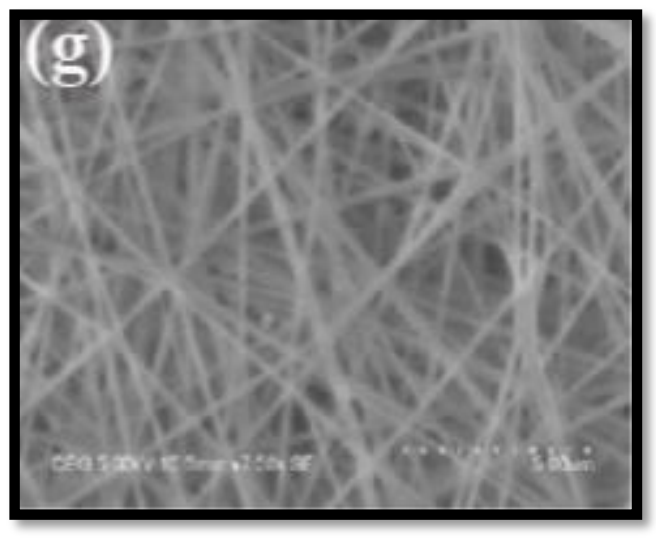

SEM IMAGE OF PCL MAT

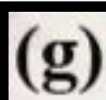

PHOTOGRAPHIC IMAGE OF PCL MAT

Figure. 10: left side shows the SEM image and the right side shows the photographic image of PCL mat.

\subsection{COST ESTIMATION}

The cost for manufacturing the centrifugal spinning machine is produced in the tabular column format where, the cost for manufacturing the machine is reduced and displayed here, 


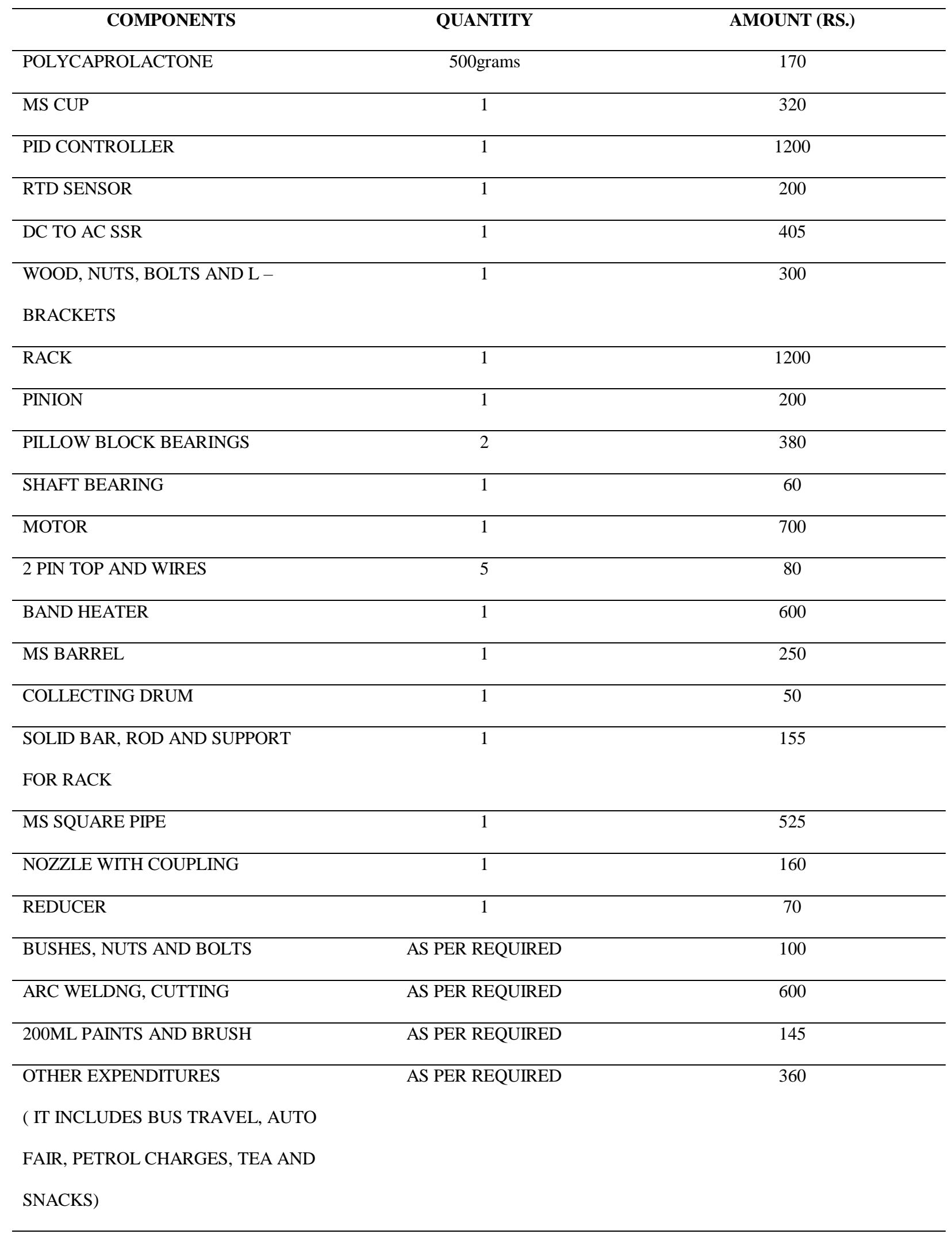

TOTOAL COST

Rs. 8,230

Table 4.1 Cost estimation 


\subsection{CENTRIFUGAL SPINNING METHOD}

It is the most commonly used method when compared to all the nano - fiber production methods because it has many advantages when compared to them, the comparison between various nano - fiber production methods are mentioned here,

\begin{tabular}{ccccc}
\hline METHOD & PRODUCTION & MATERIAL & SAFETY & COST \\
& RATE & CHOICE & & \\
CENTRIFUGAL & HIGH & BROAD & HIGH & LOW FOR INDUSTRIAL \\
SPINNING & & & PRODUCTION, MEDIUM FOR \\
& & & & ACADEMIC RESEARCH \\
\hline ELECTROSPINING & LOW & BROAD & RELATIVELY & LOW FOR ACADEMIC RESEARCH, \\
& & & LOW DUE TO THE & HIGH FOR INDUSTRIAL \\
& & & USE OF HIGH & PRODUCTION OF NANO - FIBERS \\
MELT BLOWING & HIGH & NARROW & HIGH & DUE TO LOW PRODUCTION RATE \\
\hline BI - COMPONENT & MEDIUM & NARROW & HIGH & MEDIUM \\
FIBER SPINNING & & & & \\
\hline
\end{tabular}

Table 4.2 comparison of various nano - fiber production methods 


\section{CONCLUSION}

In this paper, the nano - fibers are produced by using the optimized centrifugal spinning machine and the production of nano - fibers can be made for numerous numbers of conducive and non-conductive materials can be made by using centrifugal spinning method. Since the centrifugal centrifuge does not require high voltage, the system can alleviate safety related problems. In addition, centrifugal spinning can greatly improve production efficiency by increasing the rotational speed, enabling rapid and largescale production of nanofibers. The fibers obtained using this method have superior properties, and the process is free from the extra process of solvent recovery as no solvent is used. In this spinning process, the limitations of the electrospinning process, such as a very high electric field, low productivity, conductivity and high production costs are eliminated. Compared with the electrospinning process, centrifugal spinning allows nanofiber fabrication from the polymers at much higher concentrations, which decreases the use of solvent and lowers the production cost.

\subsection{FUTURE SCOPE}

In future it can be fully automated by the uses of sensors and other equipment's. Where, we can use hopper and level sensors, pneumatic cylinders. In this we are going to use polymers like gelatin, polyurethane and collagen granules which are loaded in a large barrels which is called as loading unit where it is connected to a hopper and the hopper is connected to a large tube with the level sensors connected at the top of the tube with the hopper's bottom end with a band heater of $1 \mathrm{KW}$ to $1.5 \mathrm{KW}$ which is called as heating unit and the fiber coming out from the spinneret is collected in a collector drum which is called as collecting unit and the fiber collected in the drum is changed by using robotic arms by changing the fiber collected drum with the empty drum and the fiber is separated from the drum and it is reused which is called as un - loading unit. Where, the level sensor is a device that is used to determine the level (or) the amount of fluids, liquids (or) other substances flowing in an open (or) closed system. Like infrared sensors, level sensors are found in a wide range of industries. They are primarily known for measuring fuel levels, but are also used in companies that work with liquid materials. For example, the recycling industry, as well as the juice and spirits industry, rely on these sensors to measure the amount of liquid assets they hold. 


\section{FUNDING}

This present work was jointly supported by Jenith Immanuel R, Harish B, and Prakash R. Funding sources were not involved in study design, data analysis and interpretation, report writing, and the decision to submit the article for publication.

\section{ACKNOWLEDGEMENTS}

Meiarul R designed and carried out the experiments, analyzed the data, discussed the results and wrote the paper.

\section{REFERENCES}

[1] Preparation and properties of polystyrene/silica fibres flexible thermal insulation materials by centrifugal spinning, polymer (2019) by Guoqin Leng, Xiaoguang Zhang, Tengteng Shi, Guo Chen, Xiaowen Wu, Yangai Liu, Minghao Fang, Xin Min, Zhaohui Huang , 02 November 2019, Publisher - Elsevier, Journal - Science Direct, Polymer, PII: S0032-3861(19)30971-1, Reference: JPOL 121964, DOI: https://doi.org/10.1016/j.polymer.2019.121964

[2] Research on the development of the centrifugal spinning machine by Zhang Zhiming, Sun Jun, 03 July 2017, Publisher - EDP Sciences, Journal - MATEC Web of Conferences 95, 07003 (2017), ICMME 2016, DOI:10.1051/matecconf/20179507003,https://www.researchgate.net/publication/313536282_Research_on_ the_development_of_the_centrifugal_spinning

[3] Centrifugal spinning: An alternative Approach to fabricate nanofibers at high speed and low cost by XIANGWU ZHANZ and YAO LU, 02 September 2014, Publisher - Taylor \& Francis Group, Journal Research Gate, Polymer Reviews, 54:4, 677-701, DOI:10.1080/15583724.2014.935858, http://dx.doi.org/10.1080/15583724.2014.935858

[4] A comparative study of $\operatorname{sio}_{2}$ (nanofibers silica) Production via two novel non - electrospinning methods: centrifugal spinning vs solution blowing by Mehmet Durmus Calisir, Alikilic, 28 September 2019, Publisher - ELSEVIER, Journal - Science Direct, Material Letters 258 (2020) 126751, DOI: https://doi.org/10.1016/j.matlet.2019.126751 
[5] Centrifugal spinning - High-rate Production of nanofibers by Chen Chen, Mahmut Dirican, Xiangwu Zhang, 11 January 2019, Publisher - ELSEVIER, Journal - Science Direct, In book: Electrospinning: Nanofabrication and Applications(pp.321-338), DOI: https://doi.org/10.1016/B978-0-323-51270-1.00010-8

[6] Fabrication and properties of carboxy methyl chitosan/polyethylene oxide composite non - woven mats by centrifugal spinning by Chen Li, Yu Huang, Renhao Li, Yun Wang, Xin Xiang, Chunhua Zhang, Dong Wang, Yingshan Zhou, Xin Liu, Weilin Xu, 31 August 2020, Publisher - ELSEVIER, Journal - Science Direct, carbohydrates polymers 251 (2021) 117037, DOI: https://doi.org/10.1016/j.carbpol.2020.117037

[7] Rotary - jet spin assisted fabrication of $\mathrm{MnO}^{2}$ microfiber for supercapacitor electrode applications by Samik Saha, Priya brata Sadhukhan, Sreya Roy Chowdhury, Sachindranath Das, 12 July 2020, Publisher ELSEVIER, Journal - Science Direct, Materials Letters 277 (2020) 128342, PII: S0167-577X(20)31047-8, Reference: MLBLUE 128342, DOI: https://doi.org/10.1016/j.matlet.2020.128342

[8] Mechanistic study on rapid fabrication of fibrous films via centrifugal melt spinning by Yan Yang, Nan Zheng, Yanjun Zhou, Weiguang Shan, Jie Shen, 4 February 2019, Publisher - ELSEVIER, Journal - Science Direct, International Journal of Pharmaceutics $560 \quad$ (2019) 155-165, DOI: https://doi.org/10.1016/j.ijpharm.2019.02.005 